\title{
Comparison of Top-Five India Based IT Services Providers through Dea Approach
}

\section{Prashant Dixit*}

Department of Management, Amity University, India

\begin{abstract}
The importance of manpower employed in IT companies is discussed and this factor is compared with top five IT Companies of India. Data for five years (from 2009 to 2013) has been collected and an analysis between Profit after Tax (PAT), and number of employees has been done. Thereafter, Data Envelopment Analysis between manpower and Profits has been done. The ratios of profitability efficiency have been calculated these figures have been compared and it has been shown that the number of employees has a very significant effect on profitability in IT companies.

DEA models can generate new alternatives to improve performance compared to other techniques. Linear programming is the backbone of DEA methodology that is based on optimization platform. Hence, what differentiates the DEA from other methods is that it identifies the optimal ways of performance rather than the averages.
\end{abstract}

\section{Introduction}

The management of information technology (IT) has become one of the critical issues that managers need to address with great care. The impact of IT has been perceived in almost every part of a business: strategic relevance, process control, research and development, customer service, coordination, Costs etc. At the same time, IT is reshaping the competition environment in which a business operates and competes.

Traditional business rules become obsolete and outdated and are no longer applicable. IT necessitates the establishment of new competition rules that focus more on speed, quality, productivity, efficiency and customer orientation.

Profitability is invariably the main spark of any economic activity. An analysis of profitability for some Information Technology companies .Of course, one must first decide the measure to test profitability. In the annual reports provided by various companies, there are several heads under which performance can be measured. These are: 'Profit after Tax' (PAT), 'Profit before Tax (PBT) and Assets created. Of these measures, there is no major difference between Profit-before-Tax and Profitafter-Tax since they both indicate the same measure of profitability. Assets created, on the other hand, may be another measure of the health of the company and the increase in assets may be a measure of the health of the company. However, assets are not normally increased in preference to increase in profit before tax or profit after tax except in very special condition which may be tax related. Therefore either may be selected. In our present case we selected "Profit after Taxes" in case of companies in India.

It is being hypothesized that the manpower strength of an organisation indicates its health. Since different companies have different levels of manpower requirements, the comparison between the increase in profitability and the increase in manpower annually, is the best way to test this hypothesis.

Data envelopment analysis (DEA) is receiving increasing importance as a tool for evaluating and improving the performance of manufacturing and service operations. It has been extensively applied in performance evaluation and benchmarking of schools, hospitals, bank branches, production plants, etc [1]. This research provides an introduction to DEA and some important methodological extensions that have improved its effectiveness as a productivity analysis tool.

\section{Motivation}

Producing information technology (IT) matters to an economy. In countries where software, hardware or IT services are generated in abundance, the contribution to gross domestic product is upwards of $5 \%$. In many countries, the IT sector has also been a major source of labour productivity growth. No wonder, then, that many governments have invested considerable energy in recent years to encourage the growth of local IT producing industries. India has been able to parlay unique factors, such as workforce size, low wages or language attributes, into strong IT sector performance, compensating for glaring weaknesses in the industry environment.

One of the difficult challenges facing management and researchers today is how to justify costly investments in information technology (IT). This report presents an approach to investigating the effects of IT on technical efficiency in a firm's production process through nonparametric frontier method of data envelopment analysis (DEA). Measuring the efficiency of any organization either private or governmental has become an interesting issue among interested researchers. The process normally focuses on different parts of an organization plans, processes as well as human resources by an adequate performance evaluation system for development and stability in today's competition field. The results of performance evaluation could help us monitor deviation from goals and targets.

\section{Problem statement}

In order to examine IT's impact on technical efficiency in the production process, we carry DEA analysis, against their respective manpower strength.

Then we examine how a firm's IT manpower strength has a favorable impact on the technical efficiency of its production process.

*Corresponding author: Prashant Dixit, Department of Management, Amity University, India,Tel: 0120-2445252; E-mail: prashantdixit786@gmail.com Received June 1, 2014; Accepted June 18, 2014; Published June 25, 2014 Citation: Dixit P (2014) Comparison of Top-Five India Based It Services Providers through Dea Approach. J Bus Fin Aff 3: 121 doi:10.4172/2167-0234.1000121

Copyright: (C) 2014 Dixit P. This is an open-access article distributed under the terms of the Creative Commons Attribution License, which permits unrestricted use, distribution, and reproduction in any medium, provided the original author and source are credited. 


\section{Scope}

This report focuses on the IT industry particularly India-based top Five players TCS, Cognizant, Infosys, Wipro and HCL in the IT industry.

This study also attempts to present a Comparison of Top-Five India Based IT Services Providers through DEA Approach.

\section{Objectives}

- To provide an overview of IT industry as a whole.

- To provide an overview of selected top Five India-based IT services providers.

- To compare the technical efficiency of selected top Five India-based IT services providers through DEA approach.

\section{Thesis Outline}

Chapter 1 consists of Introduction, motivation, problem statement, Scope and objectives of the study.

Chapter 2 consists of literature review related to my study that helps me to further proceed and to better understand the area of my interest.

Chapter 3 consists of methodology that shows the data collection source and analyses of my study.

Chapter 4 consists of Data analysis \& Findings of the study.

Chapter 5 consists of conclusions of the study.

\section{Literature Review}

The importance of manpower employed in IT companies is discussed and this factor is compared IT Companies and in non IT companies [2]. Data for ten years (from 2001 to 2010) has been collected and an analysis between Profit after Tax (PAT), number of employees and compensation paid per employee has been analyzed and the values of the correlation coefficient for each company has been collected. Data Envelopment Analysis between manpower and Profits has been done. The ratios of profitability and efficiency have been calculated these figures have been compared and it has been shown that the number of employees has a very significant effect on profitability in IT companies.

Technical efficiency analysis of information technology investments: a two-stage empirical investigation:One of the difficult challenges facing management and researchers today is how to justify costly investments in informationtechnology (IT) [3]. This paper presents an approach to investigating the effects of IT on technical efficiency in a firm's production process through a two-stage analytical study with a firm-level data set. In the first stage, a nonparametric frontier method of data envelopment analysis (DEA) is employed to measure technical efficiency scores for the firms. The second stage then utilizes the Tobit model to regress the efficiency scores upon the corresponding IT investments of the firms. Strong statistical evidence is presented to confirm that IT exerts a significant favorable impact on technical efficiency and in turn, gives rise to the productivity growth that was claimed by recent studies of IT economic value. Practical implications are then drawn from the empirical evidence.

The main purpose of the present study is to develop apposite construct to benchmark the safety performance in Indian industries [4]. Data envelopment analysis (DEA), being a robust tool, has been employed to evaluate the performance of industries. DEA, basically, takes into account the input and output components of a decision making unit (DMU), to calculate technical efficiency (TE). TE is treated as an indicator for safety performance of DMUs and comparison has been made among them. Thirty Indian organizations under three industrial categories such as construction, refractory and steel are chosen for comparison purpose. It has been observed that safety performance of construction industries is consistently low as compared to other categories ofindustries. TE has been calculated using a models called constant return to scale (CRS) of DEA.

Data Envelopment Analysis (DEA) is a relatively new "data oriented" approach for evaluating the performance of a set of peer entities called Decision Making Units (DMUs) which convert multiple inputs into multiple outputs [5]. The definition of a DMU is generic and flexible. Recent years have seen a great variety of applications of DEA for use in evaluating the performances of many different kinds of entities engaged in many different activities in many different contexts in many different countries. These DEA applications have used DMUs of various forms to evaluate the performance of entities, such as hospitals, US Air Force wings, universities, cities, courts, business firms, and others, including the performance of countries, regions, etc. Because it requires very few assumptions, DEA has also opened up possibilities for use in cases which have been resistant to other approaches because of the complex (often unknown) nature of the relations between the multiple inputs and multiple outputs involved in DMUs.

The strategic impacts of Information Technology (IT) on the organisations' performances have been of interest to both managers and researchers for decades Studies in the field have led to the suggestion that IT-enabled strategies could be used to gain competitive advantage [6]. The argument is that IT resources do offer strategic advantage to organisations through efficient and cost effective delivery of the organisation's value chain.

The contribution of IT to the improvement of various measures of organisation's performance metrics such as productivity, profitability, cost, differentiation and market share is variously termed as "IT business value", "strategic value of IT", "IT strategic advantage", "IT as competitive weapon", and "IT-dependent strategy" by different researchers [7].

TCS is an Information Technology (IT) services, consulting and business solutions company. The Company provides end-to-end technology and technology related services to global enterprises. TCS domain knowledge and technology expertise helps global corporations to focus on their core business, while TCS manages their investments in technology and helps transform their business processes [8].

Cognizant's approach to helping clients operate more efficiently, and also to reimagine their business models around emerging technology architectures, is embodied in our Three Horizon model. Horizon 1 offerings consist of core services, such as application development and maintenance, testing and system integration, which address the need to make existing operations more effective and productive. Horizon 2 and Horizon 3 includes newer services and emerging capabilities that help clients reinvent their businesses to succeed in a climate marked by dramatic changes in customer demands, markets, competition and regulation [9].

Infosys (formerly Infosys Technologies) [10] is an Indian multinational that provides business consulting, technology, engineering and outsourcing services. It is headquartered in Bengaluru, Karnataka. Infosys is the third-largest India-based IT services company by 2012 revenues, and the second largest employer 
of $\mathrm{H}-1 \mathrm{~B}$ visa professionals in the United States, as of 2012. On $28 \mathrm{March}$ 2013 , its market capitalisation was $\$ 30.8$ billion, making it India's sixth largest publicly traded company [11].

Wipro's R\&D focuses on incubating and strengthening our portfolio of IT services across multiple new and emerging technology areas. This is driven with an agenda through its focus on Applied Research, Customer Co-Innovation, investing in developing services around defined Advanced Technology Themes (Intelligence Augmentation, Immersive Experience, Smart Systems, Ubiquitous Enterprise, \& Next Generation Materials \& Manufacturing), and experimentation on Innovative Open Execution Models [12].

HCL's business strategy "Employee First, Customer Second" directs our investments to retain the right skilled professionals at the right place, right time and right cost. An initiative, Program FIRST, has been shaped to provide a differentiated experience to our employees with regard to the career, performance, reward, learning and talent management practices facilitating their growth [13].

\section{Methodology}

The study covers the top Five India-based IT services providers and their performance. Data collection is mainly based on secondary sources like - Internet, Reports Magazines, Journals, and Books.Besides this, Data Envelopment Analysis approach is adopted for Comparison of technical efficiency, keeping in mind the basic purpose of study.

Data envelopment analysis (DEA), occasionally called frontier analysis, was first put forward by Charnes, Cooper and Rhodes in 1978 [1]. It is a performance measurement technique which, as we shall see, can be used for evaluating the relative efficiency of decision-making units (DMU's) in organizations. Here a DMU is a distinct unit within an organization that has flexibility with respect to some of the decisions it makes, but not necessarily complete freedom with respect to these decisions.

There is an increasing concern with measuring and comparing the efficiency of organizational units such as local authority departments, schools, hospitals, shops, bank branches and similar instances where there is a relatively homogeneous set of units.

The usual measure of efficiency, i.e.

Efficiency=Output/Input

\section{Relative efficiency measurement}

The measurement of relative efficiency where there are multiple possibly incommensurate inputs and outputs was addressed by Farrell and developed by Farrell and Fieldhouse, focusing on the construction of a hypothetical efficient unit, as a weighted average of efficient units, to act as a comparator for an inefficient unit.

A common measure for relative efficiency is

Efficiency $=$ Weighted sum of Outputs $/$ Weighted sum of inputs

When there are multiple inputs and outputs, the best way of coming up with a single efficiency measure is as below:

$$
\left(\mathrm{w}_{1}{ }^{*} \mathrm{O}_{1}\right)+\left(\mathrm{w}_{2}{ }^{*} \mathrm{O}_{2}\right)+\ldots \ldots .+\left(\mathrm{w}_{\mathrm{m}}{ }^{*} \mathrm{O}_{\mathrm{m}}\right)
$$

Efficiency form outputs and $\mathrm{n}$ inputs

$$
\left(\mathrm{u}_{1}{ }^{*} \mathrm{I}_{1}\right)+\left(\mathrm{u}_{2}{ }^{*} \mathrm{I}_{2}\right)+\ldots \ldots .+\left(\mathrm{u}_{\mathrm{n}}{ }^{*} \mathrm{I}_{\mathrm{n}}\right)
$$$$
\text { where, } \mathrm{O}_{\mathrm{i}}=\text { Output } \mathrm{i}
$$

$$
\begin{aligned}
& I_{j}=\text { Input } j \\
& w_{i}=\text { weight applied to output } i \\
& u_{j}=\text { weight applied to input } j
\end{aligned}
$$

(Note efficiency is usually constrained to the range $[0,1]$ ).

The initial assumption is that this measure of efficiency requires a common set of weights to be applied across all units. This immediately raises the problem of how such an agreed common set of weights can be obtained. There can be two kinds of difficulties in obtaining a common set of weights. First of all it may simply be difficult to value the inputs or outputs. For example in the depot data the weights on the outputs presumably relate to the values or cost of producing the outputs but these costs or values may be difficult to measure. Alternatively different depots may choose to organize their operations differently so that the relative values of the different outputs may legitimately be different. This perhaps becomes clearer if an attempt has been made to compare the relative efficiency of schools with achievements at music and sport amongst the outputs. Some schools may legitimately value achievements in sport or music differently to other schools, and in general units may value inputs and outputs differently and thus require different weights. This measure of efficiency coupled with the assumption that a single common set of weights is required is thus unsatisfactory.

\section{The data envelopment analysis}

Charnes, Cooper and Rhodes [1] recognized the difficulty in seeking a common set of weights to determine relative efficiency. They recognized the legitimacy of the proposal that units might value inputs and outputs differently and therefore adopt different weights, and proposed that each unit should be allowed to adopt a set of weights which shows it in the most favorable light in comparison to the other units.

\section{CCR DEA model}

To allow for applications to a wide variety of activities, we use the term Decision Making Unit (=DMU) to refer to any entity that is to be evaluated in terms of its abilities to convert inputs into outputs. These evaluations can involve governmental agencies and not-forprofit organizations as well as business firms. The evaluation can also be directed to educational institutions and hospitals as well as police forces (or subdivision thereof) or army units for which comparative evaluations of their performance are to be made.

We assume that there are $n$ DMUs to be evaluated. Each DMU consumes varying amounts of $m$ different inputs to produce $s$ different outputs. Specifically, DMU consumes amount $x_{i j}$ of input $i$ and produces amount $y_{r j}$ of output $r$. We assume that $x \geq 0$ and $y_{r} \geq 0$ and further assume that each DMU has at least one positive input and one positive output value.

We now turn to the "ratio-form" of DEA. In this form, as introduced by Charnes, Cooper, and Rhodes, the ratio of outputs to inputs is used to measure the relative efficiency of the $j=0$ to be evaluated relative to the ratios of all of the $j=1,2, \ldots, n$. We can interpret the CCR construction as the reduction of the multiple-output /multipleinput situation (for each DMU) to that of a single 'virtual' output and 'virtual' input. For a particular DMU the ratio of this single virtual output to single virtual input provides a measure of efficiency that is a function of the multipliers. In mathematical programming parlance, this ratio, which is to be maximized, forms the objective function for the particular DMU being evaluated, so that symbolically 
$\max \mathbf{h}_{\mathbf{o}}(\mathbf{u}, \mathbf{v})=\sum_{\mathbf{r}} \mathbf{u}_{\mathbf{r}} \mathbf{y}_{\mathbf{r o}} / \sum_{\mathbf{i}} \mathbf{v}_{\mathbf{i}} \mathbf{x}_{\mathbf{i o}}$

where it should be noted that the variables are the $u$ 's and the $v$ 's and the $y_{o r}$ 's and $x_{i o}$ 's are the observed output and input values, réspectively, of $\mathrm{dmu}_{\mathrm{o}}$, the dmu to be evaluated.of course, without further additional constraints (developed below) is unbounded. A set of normalizing constraints (one for each DMU) reflects the condition that the virtual output to virtual input ratio of every DMU, including $=0$, must be less than or equal to unity. The mathematical programming problem may thus be stated as $\mathrm{DMU}_{\mathrm{j}}=\mathrm{DMU}_{\mathrm{o}}$

$$
\begin{aligned}
& \operatorname{Max} h_{o}(u, v)=\sum_{r} u_{r} y_{r o} / \sum_{i} v_{i} x_{i o} \\
& \text { Subject to } \sum_{r} u_{r} y_{r j} / \Sigma_{i} v_{i} x_{i j}<1 \text { for } \mathrm{j}=1, \ldots, \mathrm{n}, \\
& \underset{\mathrm{u}, \mathrm{v} \geq 0 \text { for all i and } \mathrm{r} .}{ }
\end{aligned}
$$

\section{Data analysis and findings}

Data Envelopment Analysis has been done for all these companies and the value of profitability or efficiency ratio is obtained for each year. The average of these ratios is calculated for each company. These averages for Information Technology companies are invariably highvery close to one.

In order to do this, we consider the data for each company. Data for each company has been treated as one group. Data Envelopment Analysis is run for each company, the output one gets consists of the profitability/ efficiency ratio of 1 in case of the result in the most efficient year; the results for the other years are expressed as fractions of this efficiency standard. We can conclude that if the average of this ratio for all years is high then it can be implied that manpower was effective over the entire period for which the data is analyzed. This analysis has been performed and the details are given below.

Tata consultancy services: Tata Consultancy Services or TCS is the largest IT Company from India. The company is of recent origin since it was earlier operating as a unit of Tata Sons and had a fairly large international presence then. The data available is only of recent five years and the average is very high Table 1. The significance of Employee strength in enhancing profitability is very high Figure 1.

Cognizant: The manpower practices of the company are good and that the company is peacefully improving its business activities. The DEA analysis, as depicted in the Table 2 above, indicates that the profitability or efficiency ratio is fairly high, indicating that the

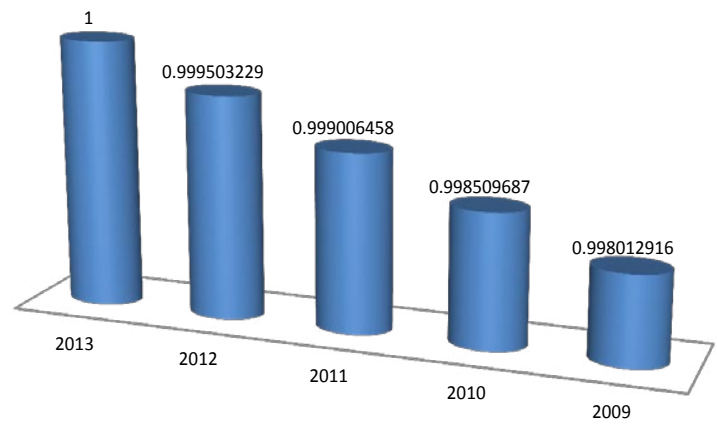

Efficiency

Figure 1: Efficiency Ratios for TCS

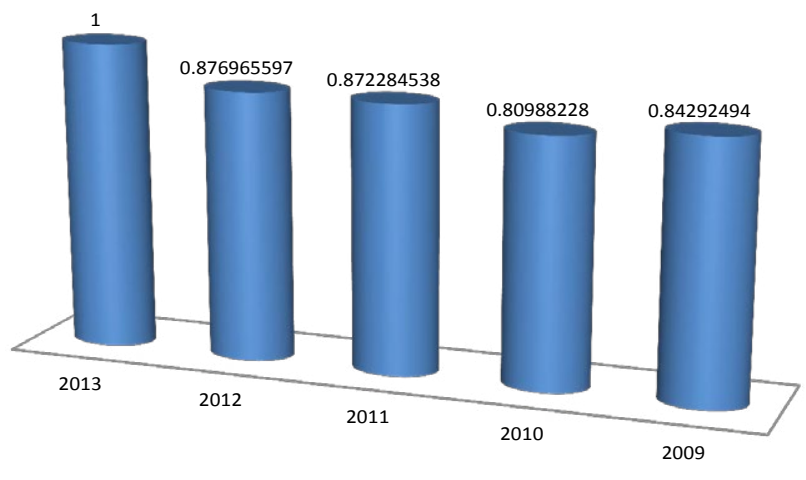

Efficiency

Figure 2: Efficiency Ratios of Cognizant

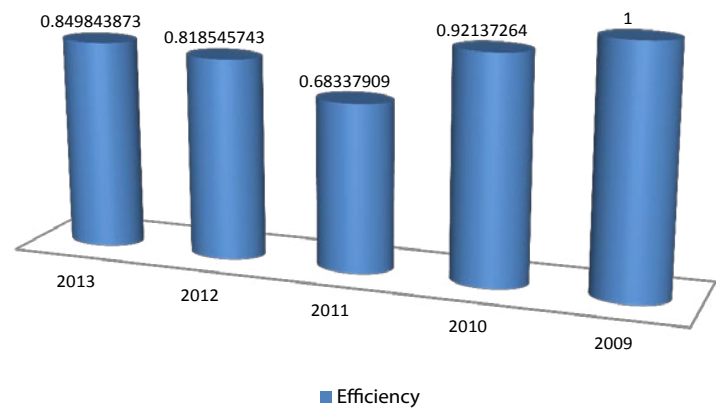

Figure 3: Efficiency Ratios of Infosys

\begin{tabular}{|c|c|l|l|l|c|}
\hline \multicolumn{7}{|c|}{ TCS } \\
\hline Years & \multicolumn{2}{|l|}{$\begin{array}{l}\text { Input } \\
\text { Number of } \\
\text { Employees }\end{array}$} & Profit(cr) & Efficiency & $\begin{array}{l}\text { Relative Effi-Technical } \\
\text { ciency } \\
\text { Efficiency }\end{array}$ \\
\hline 2013 & 276196 & $12,786.34$ & 0.046294443 & 1 & 100 \\
\hline 2012 & 238583 & 10975.98 & 0.04600487 & 0.99374498 & 99.37 \\
\hline 2011 & 168614 & $7,769.99$ & 0.046081523 & 0.995400753 & 99.54 \\
\hline 2010 & 125,619 & $5,718.51$ & 0.045522652 & 0.983328642 & 98.33 \\
\hline 2009 & 98000 & 4530.21 & 0.046226633 & 0.998535236 & 99.85 \\
\hline Average & & & & 0.994201922 & \\
\hline
\end{tabular}

Efficiency Ratio for TCS

Table 1: DEA Analysis for TCS

manpower practices of the company are good Figure 2.

INFOSYS: Infosys is perhaps the internationally most famous IT Company from India. The figures have shown in the Table 3 above show the fact of dependence of profit on manpower increase very clearly. Profitability is almost directly dependent on the manpower strength Figure 3.

WIPRO: Wipro is one of the four major IT companies in India and the results of the DEA analysis between Profit after Tax (PAT) and Number of employees over the years indicates that the Efficiency is high at 2010 Table 4 and the average efficiency is good (Figure 4).

HCL Infotech: HCL computers is one of the oldest IT companies 
Citation: Dixit P (2014) Comparison of Top-Five India Based IT Services Providers through Dea Approach. J Bus Fin Aff 3: 121 doi:10.4172/21670234.1000121

Page 5 of 6

\begin{tabular}{|c|l|c|l|l|c|}
\hline \multicolumn{7}{|c|}{ Cognizant } \\
\hline & Input & Output & & \multicolumn{2}{|l|}{ Relative } \\
Years & $\begin{array}{l}\text { Number } \\
\text { of } \\
\text { Employees }\end{array}$ & Profit(cr) & Efficiency & $\begin{array}{l}\text { Technical } \\
\text { Efficiency }\end{array}$ \\
\hline 2013 & 156700 & $7,626.20$ & 0.048667518 & 1 & 100 \\
\hline 2012 & 137700 & 5877 & 0.042679739 & 0.876965597 & 87.69 \\
\hline 2011 & 104000 & $4,415.00$ & 0.042451923 & 0.872284538 & 87.22 \\
\hline 2010 & 78,422 & $3,091.00$ & 0.03941496 & 0.80988228 & 80.98 \\
\hline 2009 & 61697 & 2531 & 0.041023064 & 0.84292494 & 84.29 \\
\hline Average & & & & 0.880411471 & \\
\hline
\end{tabular}

Efficiency Ratio for Cognizant

Table 2: DEA Analysis for Cognizant

\begin{tabular}{|c|c|c|c|c|c|}
\hline \multicolumn{6}{|c|}{ Infosys } \\
\hline & Input & Output & \multirow[b]{2}{*}{ Efficiency } & \multirow[b]{2}{*}{$\begin{array}{l}\text { Relative } \\
\text { Efficiency }\end{array}$} & \multirow[b]{2}{*}{$\begin{array}{l}\text { Technical } \\
\text { Efficiency }\end{array}$} \\
\hline Years & $\begin{array}{l}\text { Number } \\
\text { of Employees }\end{array}$ & Profit(cr) & & & \\
\hline 2013 & 156688 & $9,116.00$ & 0.058179312 & 0.849843873 & 84.98 \\
\hline 2012 & 151151 & $8,470.00$ & 0.056036679 & 0.818545743 & 81.85 \\
\hline 2011 & 137720 & $6,443.00$ & 0.046783328 & 0.68337909 & 68.33 \\
\hline 2010 & 92,000 & $5,803.00$ & 0.063076087 & 0.92137264 & 92.13 \\
\hline 2009 & 85000 & $5,819.00$ & 0.068458824 & 1 & 100 \\
\hline Average & & & & 0.854628269 & \\
\hline
\end{tabular}

Efficiency Ratio for Infosys

Table 3: DEA analysis for Infosys

\begin{tabular}{|c|c|c|c|c|c|}
\hline \multicolumn{6}{|c|}{ Wipro } \\
\hline & Input & Output & \multirow[b]{2}{*}{ Efficiency } & \multirow[b]{2}{*}{$\begin{array}{l}\text { Relative } \\
\text { Efficiency }\end{array}$} & \multirow[b]{2}{*}{$\begin{array}{l}\text { Technical } \\
\text { Efficiency }\end{array}$} \\
\hline Years & $\begin{array}{l}\text { Number } \\
\text { of } \\
\text { Employees }\end{array}$ & Profit(cr) & & & \\
\hline 2013 & 140000 & $5,650.00$ & 0.040357143 & 0.895643484 & 89.56434842 \\
\hline 2012 & 135920 & $4,685.10$ & 0.034469541 & 0.764980312 & 76.49803116 \\
\hline 2011 & 122385 & $4,843.70$ & 0.039577563 & 0.87834231 & 87.83423098 \\
\hline 2010 & 108,701 & $4,898.00$ & 0.045059383 & 1 & 100 \\
\hline 2009 & 97180 & $2,973.80$ & 0.030600947 & 0.679124848 & 67.91 \\
\hline Average & & & & 0.843618191 & \\
\hline
\end{tabular}

Efficiency Ratio for Wipro

Table 4: DEA Analysis for Wipro

\begin{tabular}{|c|c|c|c|c|c|}
\hline \multicolumn{6}{|c|}{ HCL } \\
\hline & Input & Output & \multirow[b]{2}{*}{ Efficiency } & \multirow[b]{2}{*}{$\begin{array}{l}\text { Relative } \\
\text { Efficiency }\end{array}$} & \multirow[b]{2}{*}{$\begin{array}{l}\text { Technical } \\
\text { Efficiency }\end{array}$} \\
\hline Years & $\begin{array}{l}\text { Number } \\
\text { of } \\
\text { Employees }\end{array}$ & Profit(cr) & & & \\
\hline 2013 & 65725 & $3,704.72$ & 0.056366984 & 1 & 100 \\
\hline 2012 & 50000 & $1,950.42$ & 0.0390084 & 0.692043418 & 69.2 \\
\hline 2011 & 40000 & $1,198.28$ & 0.029957 & 0.531463599 & 53.14 \\
\hline 2010 & 38,000 & $1,056.58$ & 0.027804737 & 0.493280553 & 49.32 \\
\hline 2009 & 37000 & 997.31 & 0.026954324 & 0.478193485 & 47.81 \\
\hline Average & & & & 0.638996211 & \\
\hline
\end{tabular}

Efficiency Ratio for $\mathrm{HCL}$

Table 5: DEA Analysis of HCL

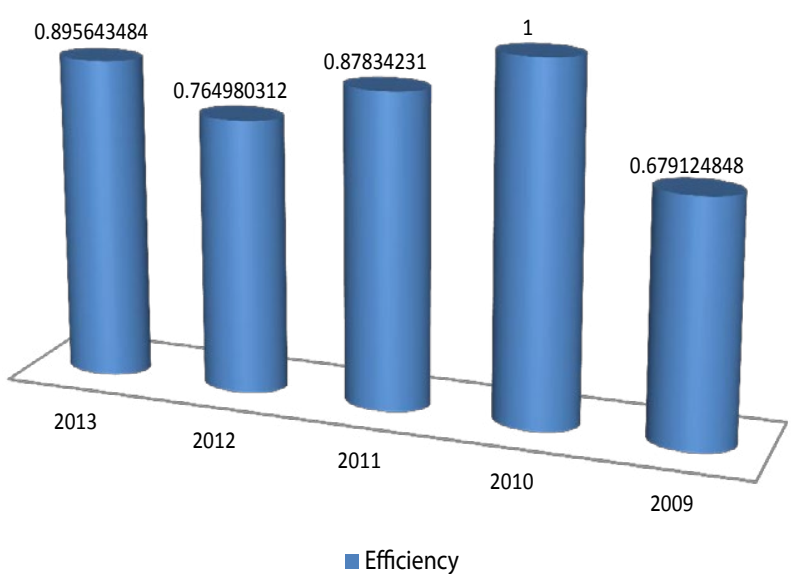

Figure 4: Efficiency Ratios of Wipro

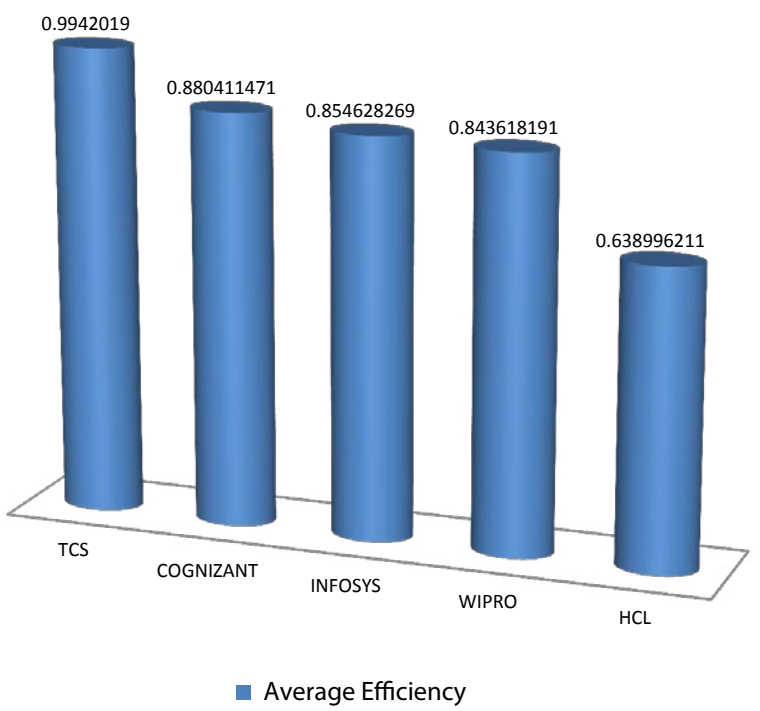

Figure 5: Average Efficiency Ratios of Top Five IT Players

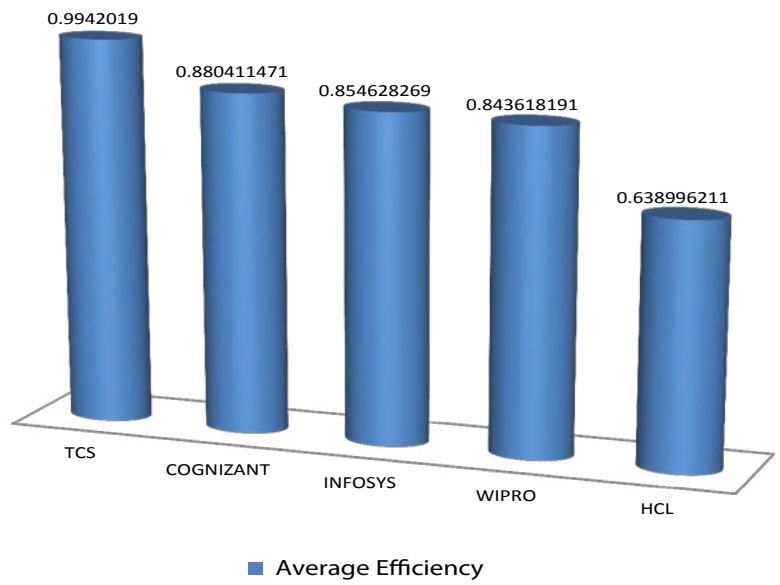

Figure 6: Average Efficiency Ratios of Top Five IT Players 
in India This is one of the four large IT companies in India whose data has been considered for analysis. One look at the above Table 5 immediately strikes one that this is a company whose growth is reflected in the continuous rise in its Profit after Tax (PAT) from 997.31 in 2009 to 3704.72 in 2013 along with the continuous rise in its manpower form 37000 in 2009to 65725 in 2013 . The value of the average efficiency calculated over this period is 0.638 (Figure 5).

\section{Comparisons of average efficiency of top players}

The analysis of the average values of profitability/efficiency ratio for each company clearly shows the dependence of profitability on manpower in IT organizations. So, As per the comparison of average efficiency of the top five India based IT services providers, TCS is more technically efficient among the other IT players. This comparison has also been presented through graphical representation Figure 6 .

\section{Conclusions}

The comparative study among top five India based IT companies clearly demonstrates that while manpower increase is related to increase in profitability. IT companies, manpower and its continuous increase is a very significant factor in the increase in profitability of the company. The average value of the efficiencies indicates this dependence. Also, the employee satisfaction is very good at the present rate of compensation per employee for IT companies. In fact it may be concluded that one of the most important assets - if not the most important asset- of an IT company is its manpower. This fact can be utilized in long term strategic planning. The factors that are required to retain the organization's most significant assets- the employees- can be analyzed. These facts may be utilized in deciding the extent, timing and composition of the training to be employed for the employees. It is a suggestion that companies should report the "attrition" rate of employees every year- subject to certain constraints: for example, the number of employees who have quit the organization after, say 3 years. The percentage of such employees out of the total employee strength will be a firm indicator of the health of the company.

To summarize the conclusions, the use of Data Envelopment Analysis indicates that manpower is a critical strategic asset for an IT organization. The fact that it appears to be a critical asset for some companies merely indicates that the manpower practices of these companies are very good; for IT companies, on the other hand manpower is a critical strategic asset. This factor must be kept in mind and given important consideration in both recruitment and training.

\section{References}

1. Charnes CA (1978-1985) united states of amerca

2. Dinkar GB (2012) Role of Manpower in IT Companies. Journal of Business Studies Quarterly, 1-33.

3. Benjamin BM, Shao WT (2002) Technical efficiency analysis of information.

4. Beriha GS (2011), A Data Envelopment Analysis Approach for Benchmarking of Safety. Singapore: IACSIT Press.

5. William W. Cooper LM (1990) Data Envelopment Analysis. J Econometrics, 1-30

6. Kassim YU (2010) Data Envelopment Analysis of IT Business Value in Engineering and Construction Organisation. The Built \& Human Environment Review,1-15.

7. Melville (2004) Piccoli and Ives, 2005; Oh and Pinsonneault.

8. TCS (2012-13) Annual report.

9. Cognizant (2012-2013) Annual report.

10. Infosys (2012-13) Annual Report.

11. Infosys (nd).

12. Wipro (2012-13) Annual Report

13. HCL (2012-13) Annual Report. 